\title{
Research on Teaching Reform of Computer Network Course in Application-Oriented Institutes
}

\author{
Xiao Jun Liu \\ School of Electronic \& Information,Huanggang Normal University,Hubei Huanggang, China \\ whutliuxiaojun@126.com
}

Keywords: Teaching Reform; Computer Networks; Modular; Task-driven

\begin{abstract}
This paper analyzes seriously the problems in the teaching of computer networks and the nature of the course, explores the integration of the modular approach and task-driven teaching thinking to do the instructional design of computer networks, in order to improve the teaching effectiveness of computer networks.
\end{abstract}

\section{Introduction}

With the expansion of higher education, application-oriented colleges emerge as the times require. Application-oriented education turns our elite education into mass education, accompanied with a serious shortage of students in learning basis, abstract thinking ability, logic, rigor and reasoning, etc. Therefore, it requires teachers who stand in frontiers in education, combining with the characteristics of students, to grope and reform the existing teaching model so as to effectively mobilize students' learning initiative, reduce the blindness of learning, enhance the teaching effect and improve teaching quality; at last cultivate applied talents with independent thinking and problem- solving ability[1-2].

Nowadays, computer network is one of the most rapidly developing technologies in the computer science and technology discipline, also an unprecedented active field in computer application. Its applications have a significant impact on today's science and technology, economy, political and military development. Meanwhile, the curriculum has become not only an fundamental course for students majoring in computer science, but also an compulsory course for Non-Computer Majors of students who major in electronics, information, e-commerce, as well as important skills and knowledge professionals who engage in computer application and IT should master[3]. Obviously, computer network course is very important. But now, the teaching effect is not good. How to improve the teaching effect in teaching process and how to arouse the enthusiasm of the students in the classroom, to make students organize knowledge system with related knowledge systematically, instead of passive acceptance of knowledge, and to solve practical problems with acquired knowledge are great challenges every teach must face..

\section{The current problems of application-oriented colleges in teaching}

Computer network course is integrated knowledge, skills and better applicability. Students are required to learn both the theoretical knowledge and practical skills. Currently, there are some major problems in teaching process[4]. These problems are as follows:

The teaching scope is limited to teaching materials which are not easy to choose[5]. Today, with the rapidly developing of computer and communication technology, new computer network technologies and related standards are emerging, while the content of teaching materials is conservative and update relatively slowly. The teachers tend to pay more attention to the interpretation of textbook knowledge, ignoring the introduction of new technologies and the extension of practical knowledge, which is bad for students to broaden their horizons and grasp the latest developments of network technology.

The problem of teacher-centered, totally dominated by teachers, lack of flexibility in teaching methods and ignoring the cognitive dominant position of students. In the computer network teaching process, most colleges take the method of multimedia teaching, combined with the computer 
simulation practice[6-8]. This cramming method of interpretation of concepts and principles tend to make an abstract and boring impression on students and lead to dogmatic memory and inertia rote learning mode. Many students lose the interest of learning this course because of the singleton pattern of teaching method. In order to cope with examinations, they choose to take in textbook focal \& difficult points passively, not competent in practical operation, also bad for them to learn the essence of computer network technology genuinely.

Inadequate attention to computer network experiments and the lack of laboratory equipment. The traditional concept of computer network experiment is mainly the verification experiment, attached to the theoretical teaching, leading to non-systematic experiment content, loose form and arbitrary behavior, which is bound to result in the disconnection between theory and practice, unable to study for application in real environment. If improper teaching, it is difficult to achieve the expected goal and effect.

Assessment Methods cannot reflect the students' real learning level. Course Assessment is a measure of mastery of knowledge. Computer network is a knowledge domain which emphasizes the theory and practical knowledge equally, so in order to assess the mastery of knowledge comprehensively, we should combine both theory and practice. While the traditional examination score cannot better balance the self-learning ability, practical ability, and innovation ability, and places more emphasis on memory capacity to the content of textbook, which tends to bring about the problem of emphasizing theory and neglecting practice and bad for the students to arouse the their enthusiasm and initiative study capability.

Therefore, we must thoroughly change the traditional teaching method, teaching conception and teaching behavior. In the teaching process, we should promote quality education more consciously and pay more attention to the role of practice teaching, in order to achieve better teaching effect. Through reading massive literature materials, the author finds that modular teaching method and task-driven teaching are applied widely in the vocational education, and may improve the self-learning ability, practical ability and creativity. The author intends to use the modular teaching as a guidance to divide the content of computer network into modules and based on the principle of task-driven, research and designs every specific module

\section{The mode of modular teaching and task-driven teaching}

MES(Modules of Employable Skills) [7], developed by ILO in the early 1970s, is based on the scene teaching and takes skill training as the core. Its idea has been generally accepted in the vocational education field, which can significantly enhance students' visibility of theory study, improve operating skills and arouse their study interest. According to the basic links in the teaching process, systematically divide curriculum structure and teaching contents into multi-goals. MES aims at dividing the complex and reciprocal chiasma curriculum structure into several basic teaching modules and its establishment promotes the scientific level in the teaching process better. First, the establishment of the system is to make the teaching behavior more standardized, make the teaching process have rules to follow, down to every step assigned to specific person. Next, in terms of content, pay more attention to the layout of teaching contents, make teaching contents more systemic and make theory more complete; from the microcosmic view, teaching layout becomes strict completely. In addition, MES can realize teaching resources optimization, share quality teaching resources and give full play to its potentials in teaching management and teaching methods.

In this paper, based on the basic principle of modular teaching and ISO / OSI architecture, by means of hierarchy network system model and systematic organizational method, the teaching contents are divided into four modules: principles and structure of computer networks, low layer communication and data transmit, network interconnection and transmission control, application service and information security. As is shown in Fig.1.

The model of teaching methods based on project task driving (a kind of upgraded teaching model of problem-inquiry) is a vigorous teaching model and established by absorbing the idea of constructivist 
teaching. According to different knowledge domains and knowledge units, it means that the teacher designs a complete study task and driven by the study task, students apply the knowledge they have learned to autonomous exploration and interactively collaborative learning by analysis and discussion. Teaching Methods Based on Project Task Driving are especailly suitable for computer networks curriculum teaching process for outstanding engineering backgound. By application of this teaching method, teachers can cultivate autonomous self-learning ability, rigorous thinking ability, independent problem-solving ability, team-work ability.

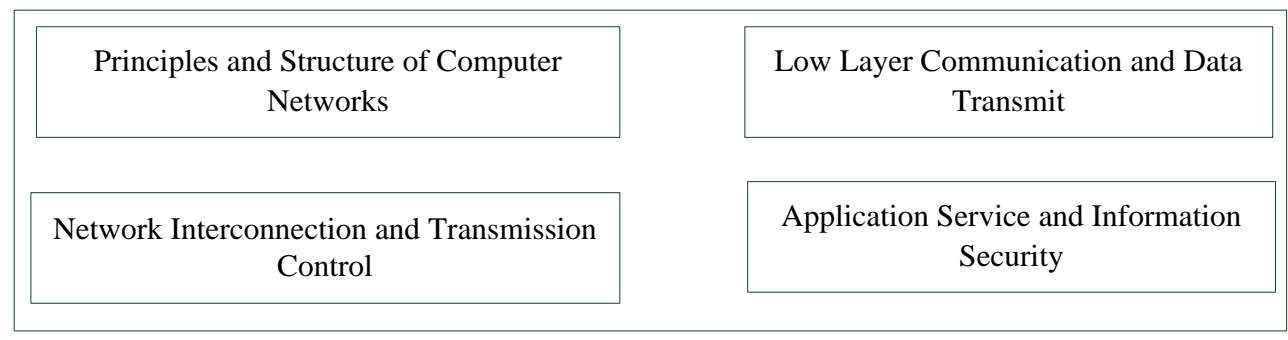

Fig. 1 four modules OF teaching contents

\section{Teaching Methods Based on Project Task Driving}

The characteristics of computer networks are the variety of concepts, complex principles and overlapping protocols and technologies which are intertwined with complexities and have both complex principles and ageing techniques. Therefore, in the teaching process, it's generally reflected that students cannot have a deep understanding of the principles and techniques in computer networks and cannot link up the knowledge points integrally. During the experiment process, the application of knowledge exists blindness. The existing classroom teaching model cannot combine theory with practice better for the purpose of improving students' ability to network technology. Our school implement computer networks education on the basis of networks hierarchical architecture and from whole to part. According to teaching methods based on project task driving of constructivism and in the design of classroom teaching methods, we conduct the task design of erery knowledge modules and take this as a supporting point to start teaching on all kinds of knowledge points. The design of teaching methods based on project task driving is divided into to 4 stages as follows[9-10].

The stage of task design based on knowledge unit. The teacher designs the study task on the basis of core knowledge points of each knowledge unit. Choose task instances based on the principle of moderate degree of difficulty, specific problems, feasible solution and stimulating interest and collectively embody core knowledge of this unit in order to make students learn to self-learning and cooperative study through the analysis, discussion and exploration.

The stage of task analysis under the guidance of teachers. Through concepts and principles taught by teachers in the classroom, help students to build problem solving methods and strategies, guide them to carry on the problem analysis and solution design and eventually form a learning task solving scheme.

The stage of task solving under the experimental environment. Students achieve the self-designing learning task scheme solving under the experimental environment. During the experiment, teachers should timely propose and induce learning knowledge contained and further explain its principles and techniques.

The stage of task evaluation by project reply. Students report their learning task completion. Teachers affirm students' good thinking methods and algorithmic thinking and supplement other theories not involved by analyzing students' problems analysis, thinking ability and practical skills for the teaching purpose of improving cognitive structure.

Teaching methods based on project task driving is the upgrade of teaching model of problem-inquiry. In computer network teaching method reform, it means the combination knowledge with experiments. Verify and learn during the experiment by designing task design containing 
knowledge points required by teaching. The divided four knowledge modules are not all suitable for the model of teaching methods based on project task driving.

Computer networks architecture and working principle knowledge units emphasize computer organization and architecture, network performance metrics and related concepts and principles, suitable for cognitive and experiential learning. It's suitable to combine traditional classroom teaching with related verified experiments.

For the underlying communication and data transmission unit of computer network, the key knowledge is about signal and signal path, coding and modulation, the transmission medium and the physical layer device, the error processing, HDLC, PPP protocol, and involving Ethernet, high-speed Ethernet ring network, wireless LAN and LAN switching of communication network. Its engineering ability is strong, and it can implement teaching mode of learning task-driven .

For the network interconnection and transmission control unit of computer network, their core knowledge is the knowledge contained in the network layer and the transport layer, including Web services model and networking, IP / ICMP protocol suite, routing algorithms and routing protocols, IP multicast and mobile IP, TCP / UDP protocol suite, and the establishment of reliable transmission. And it is the same when it comes to the teaching task-driven model.

Application services and information security knowledge units of computer network contains mainly about HTTP services, file transfer FTP, e-mail SMTP, network management SNMP, DNS, as well as socket application programming interface and access control, network detection and encryption mechanisms. It can conduct task-driven teaching through multiple learning tasks.

After the learning of all courses, teacher will conduct a holistic teaching cases of computer network systems works and the conduct interactive process of different level agreement through a network project instance. This will not only enable students to learn and master each protocol features, characteristics, composition, message formats and works, but also allow students to analyze the status, the role and the function of the various types of agreements in the whole network architecture. This ensures the integrity and completeness of the teaching content, allowing students to see the different protocols and technologies through its internal core complex local knowledge.

\section{Conclusion}

Aiming at the classroom teaching method reform and practice and based on the analysis on course characteristics, the author introduces module teaching methods and divides the contents of computer networks into four modules. Meanwhile, based on the construction of teaching methods based on project task driving, we design, analyze, implement and evaluate the study task of different knowledge modules, in order to arouse students' initiative study. The core of teaching methods based on project task driving is the construction, implementation and evaluation of the knowledge unit and normative design of knowledge task and experiment project will be the focus of future research and discussion. We will conduct further research on normalized model of knowledge task so as to push forward reform better.

\section{Acknowledgment}

The project was supported by the Teaching Research Project of Huanggang Normal University (Grant No. 2013CE30).

\section{References}

[1]. Zeng, X.-Y.: Scalability Analysis of Inter-domain Routing Architecture. Computer Knowledge and Technology ,23 (2011) 34-38.

[2]. Wang Tie, Application Study for Simulation Technology in Experimental Teaching of Computer Network Course. ECICE 2012, AISC 146 (2012) 571-577. 
[3]. Zhu, T., Gao, J.: Technology and Programming of Digital-controlled Processing course teaching reform on the basis of interactive teaching in network environment. China After School Education, 8 (2010) 75-79.

[4]. Zhao, J., Chen, M.: Exploration on computer network practical teaching reform. Science \& Technology Information ,3(2010) 75-81.

[5]. Huang, Y.: Network technology lab construction and opening experimental teaching reform. Journal of Liaoning Institute of Science and Technology, 4 (2008) 24-28.

[6]. He, J., Wu, L. Teaching reform and practice on high vocational colleges "Computer Network Base" course. Fujian Computer, 8 (2009) 45-47.

[7]. Yin Tang, Discussion on Computer Network Base Course Reform, Advances in Intelligent Systems, AISC 138 (2012) 239-244

[8]. NIU YU-bing, WANG Gong-cui, NIU Ji-lai, Research and Practice of The Experiment of Lan Technologies and Network Engineering[J];Computer Knowledge and Technology; 15(2010) 74-81

[9]. FENG Yong-li,The Explore and Practice of the Teaching of Computer Network Experiment Course[J];Computer Knowledge and Technology; 18(2010) 47-51

[10]. HE Xiao-li,SONG-Yu,ZHOU Yu-jie,Experimental Course of the Operating System and Improvement[J];Computer Knowledge and Technology; 20(2010) 21-25 